\title{
Evaluation of Redundancy for Power Generating Unit in a Cogeneration Power Plant
}

\author{
Meseret Nasir Reshid ${ }^{1}$, Mohd Amin Abd Majid ${ }^{2}$ and Masdi Muhammad ${ }^{3}$ \\ ${ }^{1}$ Department of Mechanical Engineering, Curtin University Sarawak, 98009 Miri, Sarawak Malaysia \\ 2,3 Department of Mechanical Engineering, Universiti Teknologi PETRONAS, Bandar Seri Iskandar, \\ 31750 Tronoh, Perak, Malaysia
}

\begin{abstract}
Redundancy system is very useful to enhance the performance and reliability of the power generation system of a cogeneration plant. However, the associated operating cost of redundancy system is very high. The common redundancies used in a cogeneration power plant are public utility and generator set. In order to select the best redundancy options which incurs minimum operating cost, it is required to evaluate the cost of different redundancy options. In this paper, net present value model (NPV) is developed to evaluate the cost of redundancy considering availability and reliability of the cogeneration system. Two steps applied to evaluate the redundancy cost of the cogeneration system. The first step is predicting the number of failures and downtime hours using availability and reliability analysis because redundancy is frequently used when the system failed. The second step is evaluating the cost of redundancy using NPV model. The results indicate that the use of public utility as redundancy option is costly compared to generator set option for long period of time. The major operation cost of public utility is contributed by the maximum demand charge cost which is about $57.9 \%$ of the total cost of redundancy. The study will be useful as a guide for the cogeneration operation to evaluate and select the redundancy option.
\end{abstract}

\section{Introduction}

The cogeneration system should be flexible and reliable to handle various changes in demand. In order to cope up with the situation, the cogeneration system is normally equipped with redundancy to meet the required demands [1]. A cogeneration system generates electricity continuously for a long period, but the system is expected to fail in a random manner. In case of failure event, there will be associated costs due to unexpected failure. These costs are also dependent on the type of redundancy that the cogeneration system used. Most of the cogeneration system uses public utility or generator set (Gen set) as redundancy. Public utility means the supply of electricity from national power plant to support the cogeneration plant. Gen set means gas turbine driven generator.

The redundancy system has numerous benefits in various power industries by enhancing the performance and mitigating customer damaging cost. Efforts were made by the researchers to quantify the benefits with the use of redundant systems so as to establish their significance. Pandey and Jacob [2] analysed the cost and availability of three state systems with cold standby for powerloom plant to increase the performance and expected gain over the time. In his study, the operating cost of 
redundancy is not considered. Kodama [3] performed probabilistic analysis of a warm redundancy system consisting of two dissimilar equipment assuming that the switchover device is imperfect. The author looking redundancy from performance enhancement perspective not considers the associated operation expenses. Subramanium [4] evaluated the reliability and cost of a complex redundant system. Singh et al. [5] examined the performance of an ash handling system consists of three standby elements in which two equipment were operating concurrently and the third one was cold standby. The authors used semi- Markov method. The cost benefit analyses of system availability with warm standby units and imperfect coverage have been studied by [6-10]. Under the cost/benefit criterion, comparisons were made based on assumed numerical values given to the distribution parameters, as well as to the cost of the active and standby components. As noted from the literature, the redundancy of the system has been evaluated from performance and reliability perspective. However, the use of redundancy incurs high operation cost, particularly on the cogeneration power plant due to the high connection cost to the public utility or integration of gen set. Therefore, this study will develop NPV model to assess the economic impact of the redundancy system in the cogeneration power plant.

\section{Methodology}

Two step procedures were adopted in this study. The first step is predicting frequency of failure and downtime hours using availability and reliability approach. The second step is developing NPV model to estimate the associated operating cost of redundancy.

\subsection{Prediction of failure frequency and downtime hours.}

Without reliability and availability assessment, it is difficult to predict the number of failures and downtime hours which is used as an input for consequences assessment. In this study, exponential distribution considered for the availability and reliability assessment because most of the repairable equipment or system life time is placed in the useful period of the bathtub curve [11]. Thus, the reliability and availability of repairable equipment can be obtained using Eq. (1) and (2) respectively.

$$
\begin{gathered}
R(t)=e^{-\lambda \cdot t} \\
A(t)=\frac{\mu}{\lambda+\mu}+\frac{\mu}{\lambda+\mu} e-\left({ }^{\lambda+\mu}\right) t
\end{gathered}
$$

where $\lambda$ is the failure rate and $\mu$ is repair rate of the equipment.

Based on system reliability and availability, the cumulative number of failure and downtime can be found using Eq. (3) and (4) respectively.

$$
\begin{aligned}
& N(t)=\lambda \cdot t \\
& D(t)=[1-A(t)] \cdot t
\end{aligned}
$$

where $N(t)$ is the cumulative expected number of failure and $D(t)$ is the cumulative expected down time and $\lambda$ is the system failure rate. 


\subsection{NPV model for cost estimation}

The associated operating cost of redundancy is depending on the type of redundancy used by the cogeneration plant. There are two common redundancy options are available for cogeneration system as stated in the introduction namely public utility and Genset.

\subsubsection{Cost of using public utility as redundancy}

If the system uses public utility, the system incurs maximum demand charge cost in addition to repair cost and opportunity loss. Thus, the total expected cost can be estimated by Eq. (5)

$$
\begin{aligned}
{\left[\begin{array}{l}
\text { Total Expected } \\
\text { cost of failure }
\end{array}\right] } & =\left[\begin{array}{l}
\text { Expected } \\
\text { cost of repair }
\end{array}\right]+\left[\begin{array}{l}
\text { Expected cost of } \\
\text { Maximum demand charge }
\end{array}\right]+\left[\begin{array}{c}
\text { Expected cost of electricity } \\
\text { supplied by redundancy }
\end{array}\right]+ \\
& {\left[\begin{array}{l}
\text { Expected cost of } \\
\text { opportunity loss }
\end{array}\right]-\left[\begin{array}{l}
\text { Expected } \\
\text { fuel save }
\end{array}\right] }
\end{aligned}
$$

\subsubsection{Expected Cost of repair}

The cost of repair or corrective maintenance $\left(C_{c m}\right)$ can be defined as Eq. (6).

$$
C_{c m}=N C_{r}
$$

where $N$ is the expected number of failure per year and $C_{r}$ is cost of repair per failure.

\subsubsection{Expected maximum demand charge cost}

Public utility supplies to a cogeneration plant in the incident that the Co-generator cannot meet the demand due to plant failure. Due to connection to the public utility, maximum demand charge cost is imposed when the system is connected to public utility. The maximum demand charge cost per year $\left(C_{P}\right)$ can be estimated using Eq. (7)

$$
C_{P}=N C_{M a x} K Z
$$

where $C_{M a x}$ is the Maximum demand charge cost per $\mathrm{KW}, K$ is the capacity in $\mathrm{KW}$ required per connection, and $Z$ is the percentage ratio of the system hook-up electricity from redundancy. $Z$ can be estimated using Eq. (8) based on the historical data of a cogeneration system.

$$
Z=\frac{\text { Number of hook up redundancy due to fail ure }}{\text { Total fail ure frequency }}
$$

\subsubsection{Expected Cost of supplied power by public utility}

During system outage, the plant needs to buy power from the public utility to avoid the customer damaging cost. This cost can be calculated using Eq. (9)

$$
C_{s}=D_{t} E_{R} C_{R}
$$

where $D_{t}$ is the downtime hours due to failure, $C_{R}$ is cost of electricity rate per $\mathrm{KW}$ from public utility and $E_{R}$ is the amount of energy supplied by the public utility per hour. 


\subsubsection{Loss of opportunity}

Whenever the failure occurs, the system is down for repair action. This unavailability of the system will cause opportunity loss. This loss can be represented by Eq.(10)

$$
C_{L P}=D_{t} C L
$$

where $C$ is cost per $\mathrm{KW}$ charged to clients and $L$ is the possible amount of power deliver to clients during the service outage.

\subsubsection{Fuel save}

If public utility is used as redundancy during failure event, it is not required to supply the fuel for the cogeneration system because the system is down for maintenance action. This fuel save $\left(F_{s}\right)$ can be estimated using Eq. (11)

$$
F_{s}=D_{t} C_{f} Y
$$

where $C_{f}$ is the cost of fuel per GJ and $Y$ is the amount fuel required per hour.

Therefore, the annual expected cost ( $A E C$ ) for public utility can be obtained using Eq. (12)

$$
A E C=N C_{r}+N C_{M a x} K Z+D_{t} E_{R} C_{R}+D_{t} C L-D_{t} C_{f} Y
$$

\subsubsection{Expected Cost of using Genset}

If the plant used a Genset as redundancy, three main cost need to be consider namely capital which is related to Genset installation cost, cost of repaired which is related to maintenance and fuel cost which is related to operation cost. All these costs can be represented by Eq. (13)

$$
A E C=\left[C_{i} Q\right]\lfloor A / P, i, m\rfloor+N C_{r}+D_{t} C_{f} L_{1}
$$

where $Q$ is the capacity of redundancy $C_{i}$ is the cost of installation per $\mathrm{KW}$ and $C_{f}$ is the cost of fuel to operate the Gen set and $L_{1}$ is the amount fuel required per hour .

Therefore, the net present value (NPV) can be represented using Eq. (14)[12].

$$
N P V=A E C F(P / A, i, m)
$$

where $(P / A, i, m)$ is the present worth factor, $m$ is number of years and $\mathrm{i}$ is the interest rate.

\section{Results and discussions}

\subsection{Case study}

In this study, a cogeneration power plant which has two gas turbines at $4.2 \mathrm{MW}$ capacity each is considered. These two gas turbines are linked in parallel manner to generate electricity for academic environment. The minimum threshold capacity of each gas turbine is $1497 \mathrm{KW}$. This means that if the 
gas turbine produced less than the threshold capacity, it is considered as failed. Table 1 indicated the reliability and cost parameters for the NPV evaluation of the power generation system. The values of the parameters were collected from literature, actual plant and the electricity tariffs. Mean time between failure (MTBF) and mean time to repair (MTTR) were estimated based on five years gas turbine maintenance and production data.

Table.1: Reliability and Cost parameters

\begin{tabular}{|l|l|l|}
\hline \multicolumn{1}{|c|}{ Parameters } & Unit & Values \\
\hline Cost of Maximum demand per KW & RM & 48.6 \\
\hline Cost of Electricity per KW & RM & 0.22 \\
\hline cost of repair per failure & RM & 100000 \\
\hline Cost of fuel RM per GJ & RM & 6.066 \\
\hline Fuel flow GJ per Hour & RM & 49.74 \\
\hline Investment Cost(RM) of Gen set(per KW) & RM & 1000 \\
\hline Installation Cost per KW & RM & 999 \\
\hline Required Capacity (KW) & $\mathrm{RM}$ & 4200 \\
\hline Production cost of Gen set & $\mathrm{RM}$ & 0.17 \\
\hline current demand of the campus & $\mathrm{KW}$ & 5000 \\
\hline Maximum demand & $\mathrm{KW}$ & 8400 \\
\hline MTBF & $\mathrm{Hr}$ & 264.3 \\
\hline MTTR & $\mathrm{Hr}$ & 11 \\
\hline
\end{tabular}

\subsection{Estimation of cumulative number of failure and downtimes}

Using availability and reliability analysis, the cumulative number of failures and downtime hours were estimated. Fig. 1(a) and 1(b) show that cumulative number of failure and down time of power generation through time respectively. As indicated in the plots, the simulation result was compared with actual failure frequency and downtime hours. The validation results show that the model prediction was closer to actual data. This validation results were further confirmed using t-test by considering five years observation data. The $\mathrm{P}$ value results indicate 0.095 and 0.062 for cumulative failure and down time. This means that statistically no significant different between the model and actual data as the significance value $(\mathrm{P})$ is greater than 0.05 with $95 \%$ confidence level.

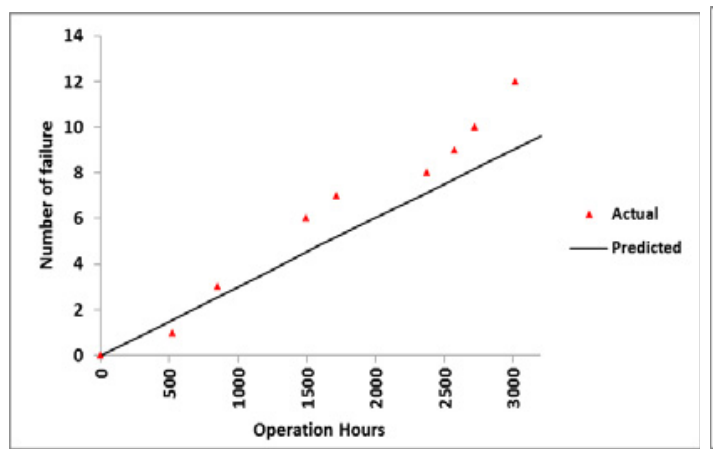

(a)Number of failures

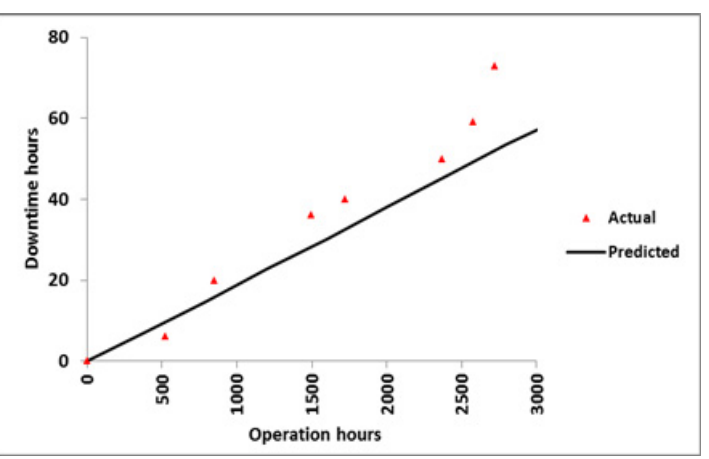

(b) Downtime hours

Figure 1: Cumulative number of failures and downtime hours 


\subsection{Redundancy Evaluation of power generation system}

The associated cost of using public utility as redundancy system is indicated in Fig. 2. The results showed that $57.9 \%$ of the redundancy cost is due to maximum demand charge cost, $35.5 \%$ is due to corrective cost, $3.7 \%$ is due to electricity hooked up from standby system during outage and $2.9 \%$ is the loss of opportunity due to production loss. This implies that most of the outage cost is contributed by maximum demand charge cost which is related with the connection of redundancy. This study proves that the use of redundancy supplied by the national electricity supplier is expensive due to maximum demand charge.

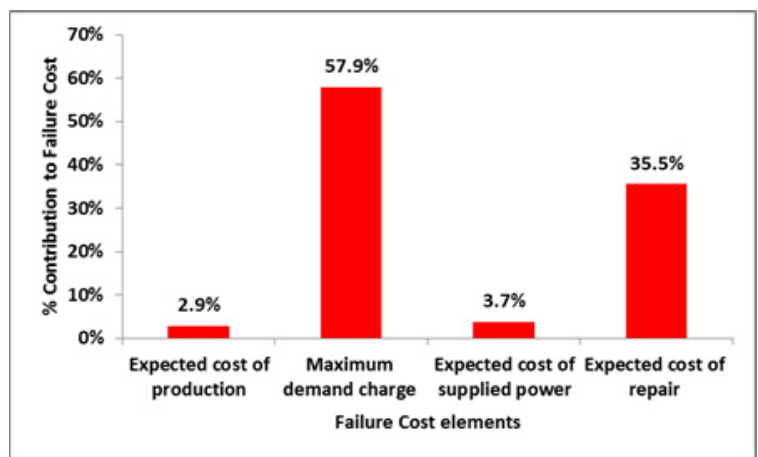

Figure 2: Contribution of failure cost

In order to select either public utility or Gen set as redundancy, it is essential to evaluate the cost of each redundancy. The redundancy option which incurs less consequence should be better options. To compare these two options, the present and annual values for 20 year life span were calculated using Eq. (12),(13) and (14). Fig. 3 shows the cumulative present cost of public utility and Gen set in twenty years' time. As can be observed from the graph, the operation year is lower than five year, the NPV of Gen set is higher than public utility which means the public utility is the better option than the Gen set if the operation period below 5 Years. When the Operation year is more than five years, the Gen set is a preferred option than public utility because the NPV of Gen set is less than the public utility redundancy option. The NPV of the public utility redundant system for 20 years was RM (11.7) million. The NPV of Gen Set was RM (9.23) million. These results indicate that using Gen set as redundancy could save $17.9 \%$ of the NPV compared to using public utility. Thus, it is better to install Gen set as redundancy for the operation period more than five years.

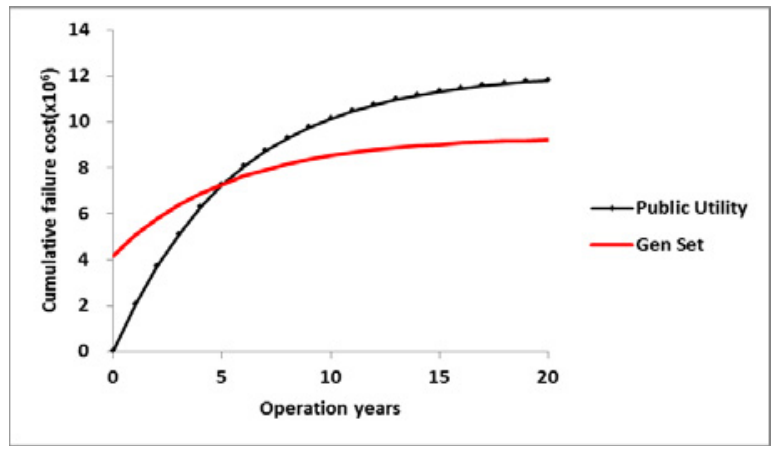

Figure 3: Comparison of Gen set and public utility based on consequence evaluation

Maximum demand charge cost, installation cost, fuel cost, installation cost and interest rate are the major factor for redundancy selection. All these factors differ from place to place and time to time. Thus, sensitivity analysis is used to explore what happens to the NPV when the estimated values of study factors are changed. To study the effect of these parameters, the spider plot is applied. The result of the spider plot is indicated in Fig. 4(a) and 4(b) for public utility and gen set redundancy options respectively. According to the spider plot theory the steeper the slop of a curve the more sensitive the 
present value (PV) is to the factor. Based on spider plot, Fig. 4(a) shows that PV using public utility is quite sensitive to maximum demand charge and MARR but insensitive to other factors. Analogously, Fig. 4(b) shows that loss of opportunity is insensitive to the PV of the Gen set but installation cost is quite sensitive to the NPV of Gen set.

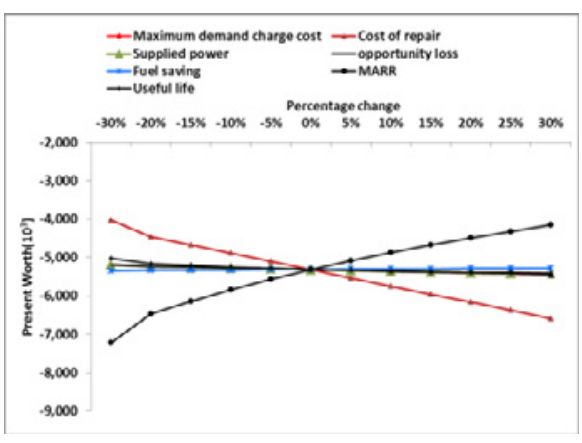

(a)

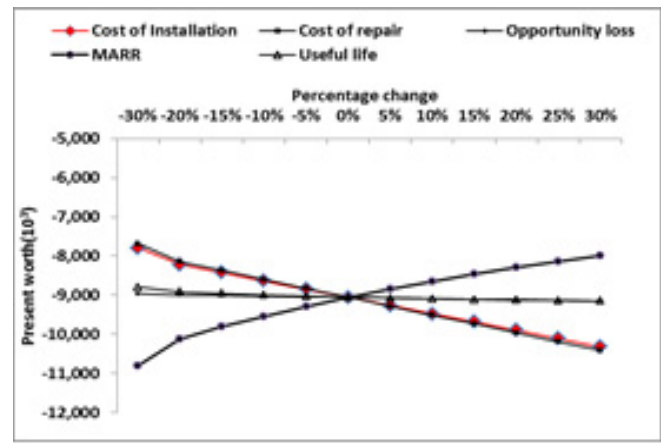

(b)

Figure 4: Sensitivity analysis for (a) public utility (b) Genset

\section{Conclusions}

In this study, the NPV model developed by incorporating availability and reliability concept to evaluate the economic effect of the redundancy system in a cogeneration system. The model was also used to evaluate different redundancy options and to select the redundancy which has minimum cost and high performance. A comparison was made between Gen set and public utility redundancy. Gen set is the better option for longer period of operations than public utility due to maximum demand charge imposed as a result of failure. In general, the developed model provides numerical information for decision making process of redundancy and performance evaluation.

\section{Acknowledgement}

Authors would like to thank Universiti Teknologi PETRONAS and MOSTI for supporting this research study.

\section{References}

1. O. Aguilar, J.Kim, S.Perry, and R.Smith, Chemical Engineering Science, vol. 63, pp. 3569-3584, 2008.

2. D. Pandey, M. Jacob, and J. Yadav, Microelectronics Reliability, vol. 36, pp. 115-119, 1996.

3. M. Kodama and J. Fukuta, 1975.

4. R. Subramanian and V. Anantharaman, Reliability Engineering \& System Safety, vol. 48, pp. 5770, 1995.

5. J. Singh and S. Garg, in International Conference on Reliability and Safety Engineering, Indian Institute of Technology, Kharagpur, 2005, pp. 497-508.

6. K.-H. Wang and C.-C. Kuo, Applied Mathematical Modelling, vol. 24, pp. 957-967, 2000.

7. K.H. Wang, Y.C. Liu, and W.L.Pearn, Mathematical Methods of Operations Research, vol. 61, pp. 329-343, 2005.

8. K. Wang and W. Pearn, Mathematical Methods of Operations Research, vol. 58, 2003.

9. K.-H. Wang and B. Sivazlian, Computers \& industrial engineering, vol. 33, pp. 129-132, 1997.

10. K. H. Wang and B. Sivazlian, Computers \& industrial engineering, vol. 33, pp. 129-132, 1997.

11. M. Rausand and A. Høyland, Wiley-Interscience, vol. 396:, 2003.

12. W. G. Sullivan, E. M. Wicks, and J. T. Luxhoj, vol. 12: Prentice Hall, 2000. 